\title{
Robustness of high-resolution regional climate projections for Greenland: a method for uncertainty distillation
}

\author{
Martin Olesen $^{1, *}$, Jens Hesselbjerg Christensen ${ }^{1,2,3}$, Eigil Kaas ${ }^{2}$, Fredrik Boberg ${ }^{1}$ \\ ${ }^{1}$ Danish Meteorological Institute, Lyngbyvej 100, 2100 Copenhagen Ø, Denmark \\ ${ }^{2}$ Niels Bohr Institute, Juliane Maries Vej 30, 2100 Copenhagen Ø, Denmark \\ ${ }^{3}$ NORCE Norwegian Research Centre, Bjerknes Centre for Climate Research, Jahnebakken 5, 5007 Bergen, Norway
}

\begin{abstract}
Managing adaptation to climate changes in Greenland will depend, to a large degree, on high-resolution climate simulations and associated uncertainty estimates. A single high-resolution climate simulation is generally insufficient to quantify the uncertainty of a given scenario projection. For Greenland, this becomes a critical issue because of a lack of high-resolution climate experiments for this region. Therefore, we introduce and test a new method to solve this uncertainty assessment problem. Using the regional climate model (RCM) HIRHAM5 over Greenland in combination with an ensemble of RCM simulations from a different geographical setting, (i.e. EURO-CORDEX), we investigate to what extent the uncertainty of projected climate change at high resolution can be evaluated from corresponding temperature spreads in a wider set of global climate models (GCMs), that is, CMIP5. The study is based on a set of time-slice simulations downscaled with HIRHAM5 at $5.5 \mathrm{~km}$ resolution for the RCP4.5 and RCP8.5 scenarios for Greenland with boundary information from the GCM EC-Earth. Our proposed uncertainty assessment method establishes a foundation on which high-resolution and relatively costly regional climate projections can be assessed as well as when using only a single RCM without the presence of analogous downscaling experiments with other RCMs and GCMs, and instead relying on existing information from CMIP5. Thus, the uncertainty of a wide range of climate indices that scales with temperature can be evaluated and quantified through the inter-model temperature spread within CMIP5.
\end{abstract}

KEY WORDS: Greenland - Climate change - Climate indices - Uncertainty quantification · Climate adaptation

\section{INTRODUCTION}

The climate in the Arctic is in rapid transition. The global mean temperature is increasing, and because of various feedback mechanisms, the Arctic region, which includes Greenland, will likely experience even faster and higher temperature increases than most other parts of the world; this is often referred to as Arctic amplification (e.g. Pithan \& Mauritsen 2014).

These temperature increases will have substantial impacts in Greenland, both in populated regions

\footnotetext{
*Corresponding author: mol@dmi.dk
}

along the coasts and on the ice sheet (AMAP 2017). Temperature changes will, and already do, require customised adaptation strategies. Infrastructure, agriculture, fishery, tourism and other sectors in Greenland are already being affected by climate change, and the impacts will increase further with increasing temperatures (Christensen et al. 2015, Rosen 2016, Lehmann et al. 2017). Related barriers and opportunities have broad political attention in Greenland, and detailed knowledge on climate change is greatly demanded by Greenlandic selfgovernance bodies (DFFL 2007).

() The authors 2018. Open Access under Creative Commons by Attribution Licence. Use, distribution and reproduction are unrestricted. Authors and original publication must be credited. 


\subsection{Climate indices}

Customised climate indices from high-resolution climate simulations are practical and valuable for local sector adaptation strategies in Greenland. Length and onset of the growing season and number of frost days are examples of highly useful climate indices designed for climate adaptation of agriculture in southern Greenland (Christensen et al. 2015, Lehmann et al. 2017). Definitions of climate indices in this study are from Persson et al. (2007), who involved the Swedish Commission of Climate and Vulnerability and other stakeholders in selecting and defining relevant climate indices with a focus on northern Europe.

Climate indices can be used to infer complex weather-dependent relations in a simpler manner than by using observed meteorological conditions or direct model output data from climate models. More than 60 different climate index projections with a

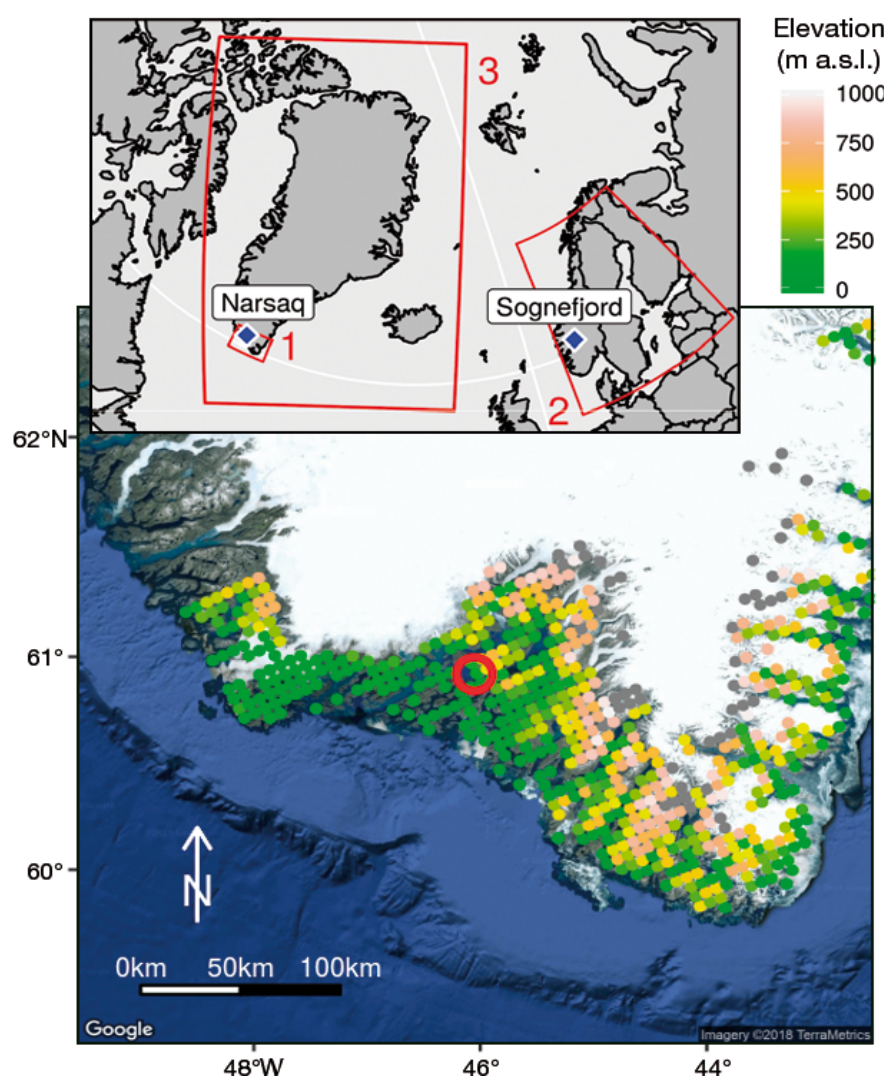

Fig. 1. Model topography in southern Greenland represented as ice-free HIRHAM5 grid points on land around the village of Narsaq (marked with a red circle). The colour map corresponding to Domain 1 in the inset has a horizontal resolution of $5.5 \mathrm{~km}$. Scandinavia (Domain 2) and the head of Sognefjord are subject to further analysis in this study. Domain 3 represents the lateral boundary of this HIRHAM5 simulation. Narsaq and the head of Sognefjord are marked with blue diamonds in the inset focus on Greenland were published by Christensen et al. (2015), targeting climate adaptation needs in Greenland. The focus was on the relatively small part of Greenland where the population is settled, and the work resulted in 6 district reports targeting the administrative level of Greenlandic municipalities. In these reports, the idea of assessing the projected index uncertainty for a single high-resolution regional climate simulation with the use of CMIP5 was introduced but never formally validated.

\subsection{High-resolution information from regional climate models}

Optimising adaptation to the future climate in Greenland requires high-resolution climate simulations to capture climate impacts in the inhabitable coastal areas, where topography is highly complex with steep mountains and complex meandering coastlines, multiple glaciers and fjord systems.

Dynamical downscaling of a global climate model (GCM) will in general and for Greenland in particular add value to the existing climate information for historical simulations as well as for future climate projections (Lucas-Picher et al. 2012, Rummukainen 2016). Fig. 1 illustrates the geographical resolution when downscaling the GCM EC-Earth (Hazeleger et al. 2012) to $5.5 \mathrm{~km}$ with the regional climate model (RCM) HIRHAM5 (Christensen et al. 2006). This distance $(5.5 \mathrm{~km})$ is just enough to resolve the fjords surrounding Narsaq in southern Greenland and, hence, distinguish and identify fjord and mountain weather characteristics. The spatial resolution is illustrated in Fig. 1, where only ice free land points are represented with coloured dots. Especially when the climate indices are based on high temporal resolution (daily values) and conducted on the basis of finescale features, the added value by using very high resolution RCMs has been demonstrated and summarised previously (e.g. Christensen \& Christensen 2003, Christensen et al. 2007, Feser et al. 2011, Lucas-Picher et al. 2012, Di Luca et al. 2015, Mayer et al. 2015, Rockel 2015, Giorgi et al. 2016).

\subsection{Uncertainty assessment}

The uncertainties associated with projected climate index changes under a given climate scenario have to be evaluated and quantified to ensure a robust scientific base for climate adaptation planning. The present work provides supporting documenta- 
tion for the uncertainty assessments of simulated climate index changes for Greenland adopted by Christensen et al. (2015).

So far, uncertainties associated with downscaling of climate projections have primarily been based on using results from an ensemble of RCMs nested in different GCMs (e.g. Pan et al. 2001, Déqué 2007, Jacob et al. 2014, Vautard et al. 2014). However, because of limited computer resources, multiple high-resolution simulations (such as those presented in this study) are so far not available for large, remote and sparsely populated regions like Greenland. Since a single regional climate simulation is insufficient for any proper uncertainty analysis (e.g. Sloth Madsen et al. 2012, IPCC 2013, McSweeney et al. 2015), an alternative method to evaluate the uncertainties related to a single climate simulation is required. Here such a method is proposed and evaluated.

\subsection{Pattern scaling}

The method builds on the theoretical scalability assumption, where there is a linear relation between annual mean temperature change (here from the GCM) and the response of a temperature-dependent variable (here the climate indices) (Mitchell et al. 1999, Tebaldi \& Arblaster 2014). The technique is an attempt to estimate the anomaly in a climate variable for a particular location or grid point for a given period that would have been obtained from additional regional climate simulations for a specific scenario.

In this study, we are not confining ourselves to simple linear relations between the climate index and annual mean temperature. On the other hand, we are not extrapolating beyond existing high-end scenario

Table 1. GCM-RCM matrix with available EURO-CORDEX experiments for Europe for the RCP4.5 and RCP8.5 scenarios at $0.11^{\circ}$ spatial resolution from 2006 to 2100 . EXP numbers refer to downscaling experiments in Figs. 7 \& 8. GCM: general climate model; RCM: regional climate model

\begin{tabular}{|lccccc}
\hline $\begin{array}{l}\text { GCM- } \\
\text { RCM- }\end{array}$ & $\begin{array}{c}\text { CNRM } \\
\text { CERFACS- } \\
\text { CNRM-CM5 }\end{array}$ & $\begin{array}{c}\text { ICHEC-EC } \\
\text { EARTH }\end{array}$ & $\begin{array}{c}\text { IPSL- } \\
\text { CM5A-MR }\end{array}$ & $\begin{array}{c}\text { MOHC- } \\
\text { HadGEM2-ES }\end{array}$ & $\begin{array}{c}\text { MPI-M } \\
\text { MPI-ESM-LR }\end{array}$ \\
\hline $\begin{array}{l}\text { DMI-HIRHAM5 } \\
\text { SMHI-RCA4 }\end{array}$ & EXP 2 & EXP 7 & & & \\
KNMI- & & EXP 5 & EXP 8 & EXP 11 & EXP 14 \\
RACMO22E & & EXP 10 & & \\
EXP 6 & & EXP 3 & & \\
CLMcom & EXP 1 & & EXP 9 & EXP 12 \\
MPI-REMO & & & & EXP 13 \\
& & & & & EXP 15 \\
\hline
\end{tabular}

temperature ranges either. The analysis presented here is performed within a temperature range, where the relationship between the climate index and the annual mean temperature is identified.

\section{METHODS}

\subsection{Models}

The model configuration we want to test in this study is the RCM HIRHAM5 (Christensen et al. 2006) set up with a $5.5 \mathrm{~km}$ spatial resolution for a domain covering Greenland and Iceland (Lucas-Picher et al. 2012, Langen et al. 2015, Boberg et al. 2017), domain 3 in Fig. 1. HIRHAM5 is nested within the GCM ECEarth, is forced with 6 hourly lateral boundaries and receives sea surface temperatures and sea ice coverage on a daily basis. EC-Earth was developed by the EC-Earth consortium (Hazeleger et al. 2012), and the version used in this study is configured at a $125 \times$ $125 \mathrm{~km}$ resolution (T159) and uses 62 vertical layers. With this setup, 5 different $20 \mathrm{yr}$ time slices are downscaled for 3 periods, 1991-2010 (a historical run), 2031-2050 (for RCP4.5 and RCP8.5) and 20812100 (for RCP4.5 and RCP8.5). Notice that the reference period for this run differs from the standard reference period (1986-2005).

To verify the propounded uncertainty assessment method, the focus is shifted to Europe, where multiple high-resolution downscaling experiments are available within the COordinated Regional climate Downscaling EXperiment for Europe (EUROCORDEX) (Jacob et al. 2014). The EURO-CORDEX11 (hereafter referred to as CORDEX) ensemble as of July 2017 contains 5 GCMs and 6 RCMs combined as 15 downscaling experiments for the RCP4.5 and RCP8.5 scenarios for Europe on $0.11^{\circ}$ (approximately $12 \mathrm{~km}$ ) resolution; the GCM-RCM matrix is shown in Table 1. For climate index calculation, both temperature and land area fraction fields are required. The RCMs used in this study are CCLM (Rockel et al. 2008), HIRHAM5 (Christensen et al. 1998, 2006), ALARO-0 (Giot et al. 2016), RACMO2 (van Meijgaard et al. 2012), RCA4 (Kupiainen 
et al. 2011, Samuelsson et al. 2011) and REMO (Jacob et al. 2012). Furthermore, 18 EUROCORDEX EURO-44 combinations are applied for larger area studies.

We use 39 GCMs from CMIP5 (Taylor et al. 2012) with spatial resolutions ranging from $0.5^{\circ}$ to $4^{\circ}$. Here we use the entire set for projected temperature changes in RCP8.5 by the end of the 21 st century. From CMIP5, a subset of 5 GCMs is used for the EUROCORDEX downscaling experiments: EC-Earth (Hazeleger et al. 2012), CNRM (Voldoire et al. 2013), IPSL (Dufresne et al. 2013), MOHC HadGEM2 (Collins et al. 2011) and MPI-M-MPI-ESM-LR (Giorgetta et al. 2013).

\subsection{Technique for uncertainty assessment}

Our hypothesis is that uncertainty related to a single high-resolution downscaled regional climate projection can be assessed by converting statistical information deduced from CMIP5 to the single highresolution downscaled projection. The overall idea is to convert the spread of annual mean temperature from CMIP5 simulations for a given RCP scenario into the uncertainty of an RCM-derived climate index, e.g. growing season onset or growing season length for the same scenario. Conversion of CMIP5 temperature spread is done through a correlation setup between an RCM-derived climate index and GCM temperatures as explained through the following steps (this subsection). The concept is also illustrated in Fig. 2.

Temperature-dependent climate indices are calculated from the highresolution RCM simulation (in this study HIRHAM5). Here we test the indices growing season length and onset, both of particular relevance for southern Greenland. Growing season length is defined as the number of days between the first occurrence of at least 4 consecutive days with daily mean temperatures above $5^{\circ} \mathrm{C}$ and the first occurrence of 4 consecutive days with a temperature below $5^{\circ} \mathrm{C}$.

RCM-derived climate indices are shown against corresponding annual mean temperature at the nearest grid point from the forcing GCM in which the RCM is nested (in this study ECEarth). This is done for index and temperature changes for each model year with respect to the mean climatology for a baseline period (1986-2005), also used by IPCC (2013).

A linear or second-order regression line, as well as confidence and prediction (tolerance) intervals, are then fitted to the RCM-derived climate indices and corresponding GCM annual mean temperatures. Following the IPCC definition of likely (66-100\% probability) on the likelihood scale (Mastrandrea et al. 2011), confidence and prediction levels are accordingly set to $66 \%$. The confidence interval relates to the best fitted regression line, whereas the prediction interval represents the year-to-year variability in the climate index. The prediction interval embraces $66 \%$ of the simulated growing season lengths for a given temperature interval, shown as the blue lines enclosing $66 \%$ of the points in Fig. 2.

Finally, the likely range of 20 yr mean temperature projections from CMIP5 can be converted to a measure of index uncertainty through the intersect with the best fitted regression line, as illustrated with colour-shaded vertical and horizontal bars in Fig. 2.

The estimated index uncertainty depends on the correlation strength and the slope of the regression line. A low correlation coefficient will expand the uncertainty range, and vice versa, a high coefficient will narrow the index uncertainty range towards the corresponding likely range of GCM annual mean temperature projections. The slope of the regression line is a measure of the index's sensitivity to temper-

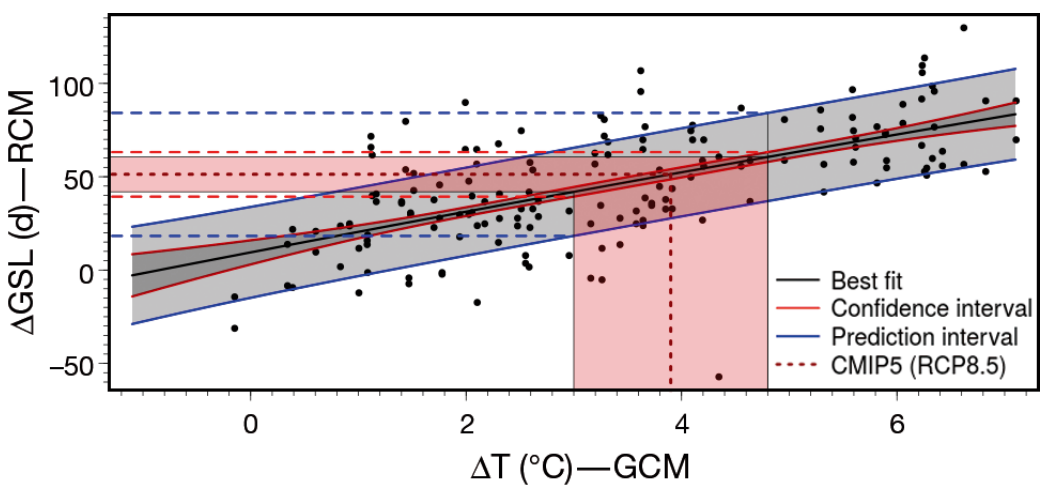

Fig. 2. Changes in growing season length (GSL) for the Sognefjord grid point (1986-2005). Each dot represents change in GSL for 1 yr from HIRHAM5 as a function of annual mean temperature $(\mathrm{T})$ change from EC-Earth for a historical run (1951-2005) and an RCP8.5-scenario run (2006-2100). The black line is the best fitted regression line, and its confidence interval (95\% confidence level) is indicated with red lines. The blue lines with grey shading in between are the prediction intervals indicating the year-to-year variability of the GSL for a given temperature change. CMIP5 temperature change in the period 2081-2100 for the RCP8.5 scenario is shown as the vertical dashed red line, and the red shaded area indicates the likely spread of the 39 CMIP5 models. Horizontal dashed lines point to the level of projected change in GSL for CMIP5 mean temperature change and corresponding likely spread (in dark and light red, respectively), and that combined with the likely range of year-to-year GSL variability (blue dashed lines). RCM: regional climate model; GCM: global climate model 
ature and hence climate change. The uncertainty range can be deduced from where the CMIP5 shaded areas intersect with the regression lines for confidence and prediction intervals shown in Fig. 2. From this example, the likely increase in number of growing season days for the RCP8.5 scenario by the end of the century can be read to $51 \pm 12 \mathrm{~d}$. To this uncertainty estimate we can now add the year-to-year variability range of the index from where the CMIP5based fit intersects with the blue prediction lines. The change in growing season length will then be $51 \mathrm{~d}$ with a total uncertainty of $\pm 33 \mathrm{~d}$.

The current uncertainty assessment method is based on the so-called delta change bias correction approach, which according to (Maraun 2016) is not a real bias correction but rather a way to employ the climate change response from the RCM to adjust the observations. But it also provides a simple measure of model agreement on the climate change signal (Giorgi \& Mearns 2003), which is what we are interested in here. Furthermore, it facilitates interpretation and direct use of estimated climate index changes and associated uncertainties in a climate adaptation context. With this technique, changes in climate indices can in this sense be directly added to current observations.

Through a statistically significant correlation between an RCM-derived climate index and the corresponding driving GCM annual mean temperature, the likely spread of the GCM ensemble for that region can be translated into a projected climate index uncertainty. This method allows for quantifying the uncertainty of climate index changes on very local scales, here simulated with a single highresolution RCM.

Whereas the application of the method is motivated by the need for high-resolution climate simulations for Greenland, the method needs an ensemble of RCMs and GCMs to be tested. Available simulations from Arctic CORDEX (Giorgi et al. 2009, Akperov et al. 2018) are insufficient and only available at coarse resolution (50 km grid). Therefore, the uncertainty assessment method is evaluated for northern Europe, where the number of downscaling experiments is much larger and performed at more comparable resolution. We focus on Scandinavia, which for some areas has somewhat similar climate characteristics to the populated areas in southern Greenland. Finally, the tested uncertainty assessment method is applied to the highresolution HIRHAM5 simulations first over a Norwegian site, Sognefjord, and then over Greenland, with a focus on Narsaq (see Fig. 1).

\subsection{Assumptions}

The index uncertainty assessment method requires the following 4 assumptions to be fulfilled:

\subsubsection{Assumption I-HIRHAM5 index and EC-Earth temperature correlation}

A statistically significant correlation between a HIRHAM5-derived climate index and the EC-Earth simulated annual mean temperature is necessary to ensure a meaningful uncertainty conversion. A strong correlation leads to relatively low uncertainties for projected climate indices, whereas a weak correlation coefficient indicates relatively large uncertainties.

Temperature-dependent climate indices are calculated from the HIRHAM5-EC-Earth downscaling (also part of EURO-CORDEX) for Sognefjord. A linear regression model including confidence and prediction intervals is fitted to the HIRHAM5-derived climate indices and corresponding annual mean temperature from the driving model, EC-Earth, as in Fig. 2. This is done for a number of climate indices (here only growing season length and onset are shown as our first choice, but we also briefly discuss number of frost days and consecutive dry days) and tested on specific locations as well as for the Scandinavian region as a whole.

\subsubsection{Assumption II-General RCM index and GCM temperature correlation}

The method requires that the correlation between a HIRHAM5-derived climate index and the corresponding EC-Earth simulated annual mean temperature represents a general index-temperature dependency. In addition, the projected temperature from HIRHAM5 should be drawn from the same distribution as the CORDEX ensemble. Some climate indices involve thresholds, and may therefore be sensitive to biases.

The consistency of index-temperature correlations among the individual CORDEX downscaling experiments (HIRHAM5-EC-Earth included) is therefore tested to ensure that HIRHAM is representative for the CORDEX ensemble. Furthermore, HIRHAM5 and 7 other RCM downscaling experiments forced with the European reanalysis dataset ERA-Interim from the European Centre for Medium-Range Weather Forecasts (Dee et al. 2011) are also compared to show individual performances with identical boundary conditions as also shown by Christensen et al. (2008). 


\subsubsection{Assumption III-}

Transferability of index relation

The derived relationship between HIRHAM5 indices and EC-Earth temperature has to be transferable from one region to another. If the relationship between HIRHAM5 and ECEarth for Scandinavia holds for Greenland, we assume that the general RCM index and GCM temperature dependency (Assumption II) sustains.

To test the transferability assumption, a climate index correlation analysis for Europe at a grid point near Sognefjord is compared to a corresponding analysis for Greenland at a grid point near Narsaq (see locations in Fig. 1). Narsaq is relevant because of its agriculture activities. The Sognefjord grid point is relevant because it is comparable to Narsaq, with its location in a west-facing fjord system at the same latitude and its similar orographically influenced weather systems.

\subsubsection{Assumption IV- CMIP5 and CORDEX variance}

The likely range of projected temperature from CMIP5 has to embrace the likely temperature range on a smaller scale from the CORDEX projections. If the likely RCM temperature range exceeds the likely GCM temperature range, we will not necessarily capture a full $66 \%$ likely range from CMIP5.

To check this, the 17th and 83rd percentiles of CMIP5 and CORDEX temperature projections are compared to make sure that the boundaries of the likely ranges are overlapping at both the high and low ends of the projected temperature distribution.

\section{RESULTS}

\subsection{Assumption I}

In Fig. 3, the change in growing season length (1986-2005) calculated from (EURO-CORDEX based) HIRHAM5 on a $12 \mathrm{~km}$ spatial resolution is shown as a function of corresponding annual mean temperature from the forcing GCM, EC-Earth. The correlation coefficient of the linear regression is $\mathrm{r}=$
0.78. The growing season onset is shown in Fig. 4 and has a lower correlation $(\mathrm{r}=0.59)$.

Moving from one grid point to the entire Scandinavian domain (Domain 2 in Fig. 1), the correlation coefficients for each grid point are shown for growing season length and onset in Figs. 5 \& 6, respectively. As the correlation between the climate index and the annual mean temperature is statistically significant, this assumption is fullfilled. The correlation between the climate index and the annual mean temperature differs across Scandinavia but remains in the range of 0.6 to 0.9 for growing season length and -0.8 to -0.4 for growing season onset, as highlighted in the density plots (top left) in Figs. 5 \& 6.

\subsection{Assumption II}

The correlation between climate indices (growing season length and onset) and annual mean temperatures among the individual regional and global models within EURO-CORDEX is compared and shown in Figs. 7 (length) \& 8 (onset) for Scandinavia and the Sognefjord grid point.

Annual mean temperatures for Scandinavia from the 15 EURO-CORDEX members are close to being normally distributed, and a Student's $t$-test is used to test the null hypothesis: HIRHAM5 simulations are indistinguishable from the CORDEX ensemble of an- 


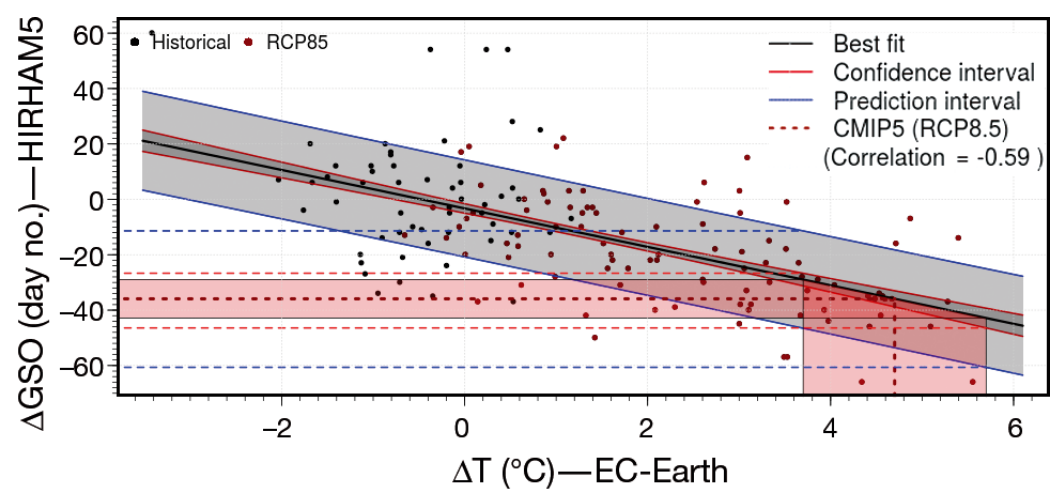

Fig. 4. Changes in growing season onset (GSO) for the Sognefjord grid point (1986-2005). Each dot represents change in GSO given as annual values from HIRHAM5 as a function of annual mean temperature (T) change from ECEarth for a historical run (1951-2005, black dots) and an RCP8.5-scenario run (2006-2100, red dots). The black line is the best fitted regression line, and its confidence interval (95\% confidence level) is indicated with red lines. The blue lines are the prediction intervals indicating the year-to-year variability of the growing season length for a given temperature change. CMIP5 temperature change in the period 2081-2100 for the RCP8.5 scenario is shown as the vertical dashed red line, and the red shaded area indicates likely spread of the 39 CMIP5 models. Horizontal dashed lines point to the level of projected change in GSO for CMIP5 mean temperature change and corresponding likely spread (in dark and light red, respectively), and that combined with the likely range of year-to-year GSO variability (in blue)

nual mean temperatures. The resulting test confirms that HIRHAM5 is indistinguishable from the merged EURO-CORDEX evaluation experiments and cannot be rejected at the $95 \%$ confidence level. The box and whiskers plots (see Fig. 12) support this finding.

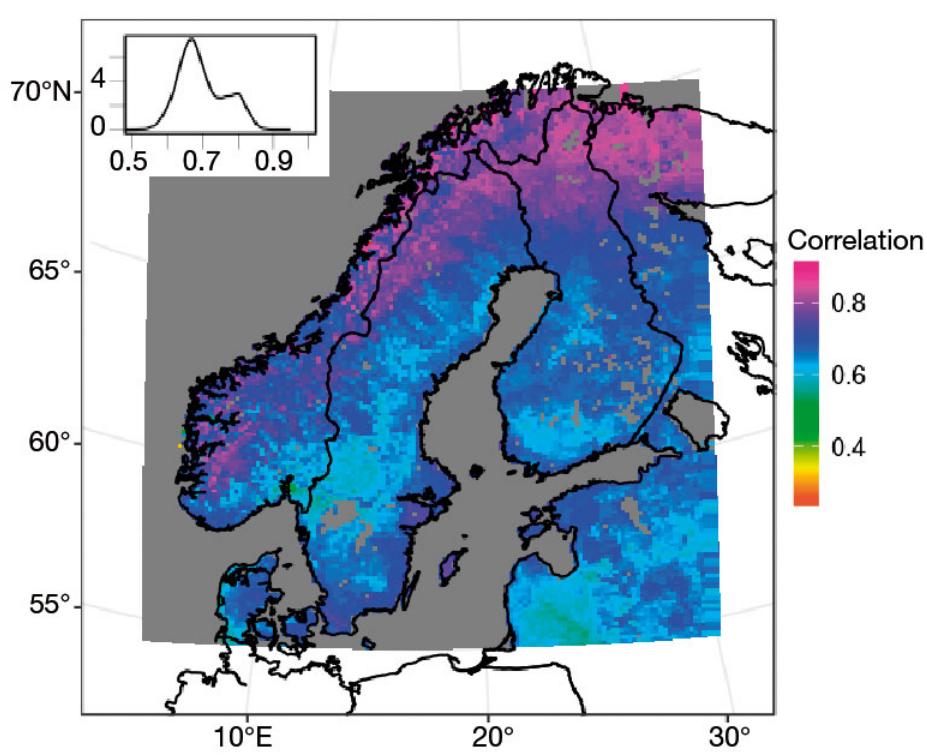

Fig. 5. Correlation coefficients between growing season length from HIRHAM5 and annual mean temperature from EC-Earth for Scandinavia for the RCP8.5 scenario from 2006 to 2100 . Inset: density of correlation coefficients

\subsection{Assumption III}

The relationship between climate indices from HIRHAM5 and annual mean temperature from EC-Earth holds for both Sognefjord and Narsaq. Fig. 9 shows a statistically significant correlation between climate index changes and changes in annual mean temperature for both the Sognefjord grid point $(r=0.78)$ and the Narsaq grid point $(r=0.75)$. The slopes of the 2 regression lines are different though, $17 \mathrm{~d}^{\circ} \mathrm{C}^{-1}$ for Sognefjord and $11 \mathrm{~d}^{\circ} \mathrm{C}^{-1}$ for Narsaq.

\subsection{Assumption IV}

The 17th and 83rd percentiles (representing the likely range) of CORDEX and CMIP5 projected annual mean temperature are compared by subtracting the respective percentiles based on CORDEX from those based on CMIP5 and displayed in Fig. 10. For blue (red) areas, the CMIP5 percentiles are lower (larger) than corresponding CORDEX percentiles. The GCMs are remapped to the CORDEX grid with nearest neighbour weights.

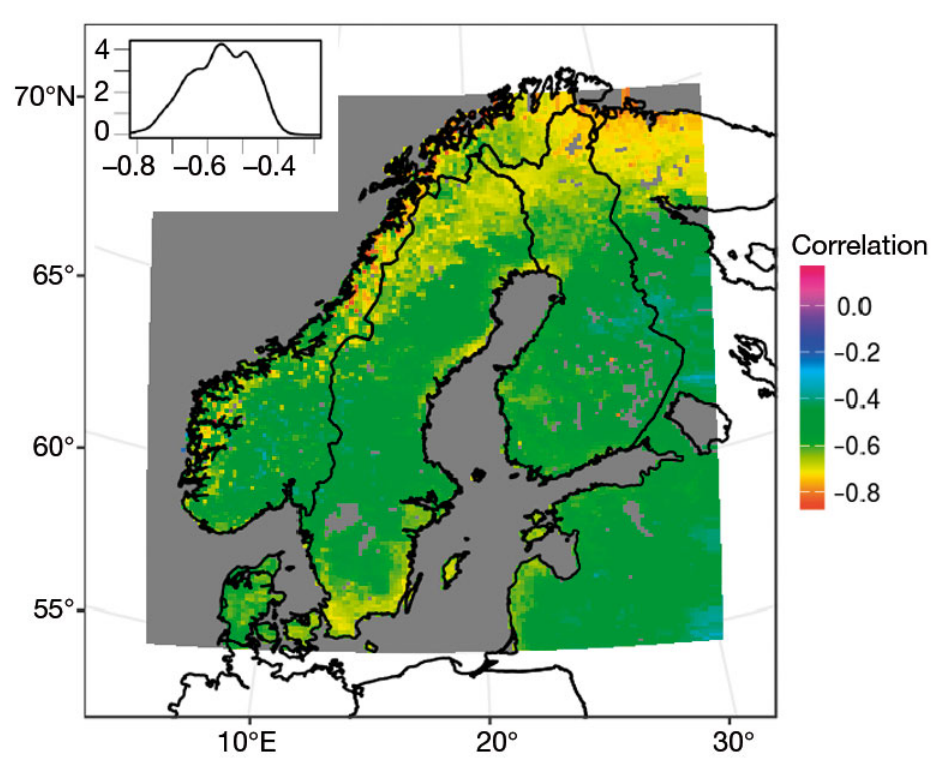

Fig. 6. Correlation between growing season onset from HIRHAM5 and annual mean temperature from EC-Earth for Scandinavia for the RCP8.5 scenario from 2006 to 2100. Inset: density of correlation coefficients 


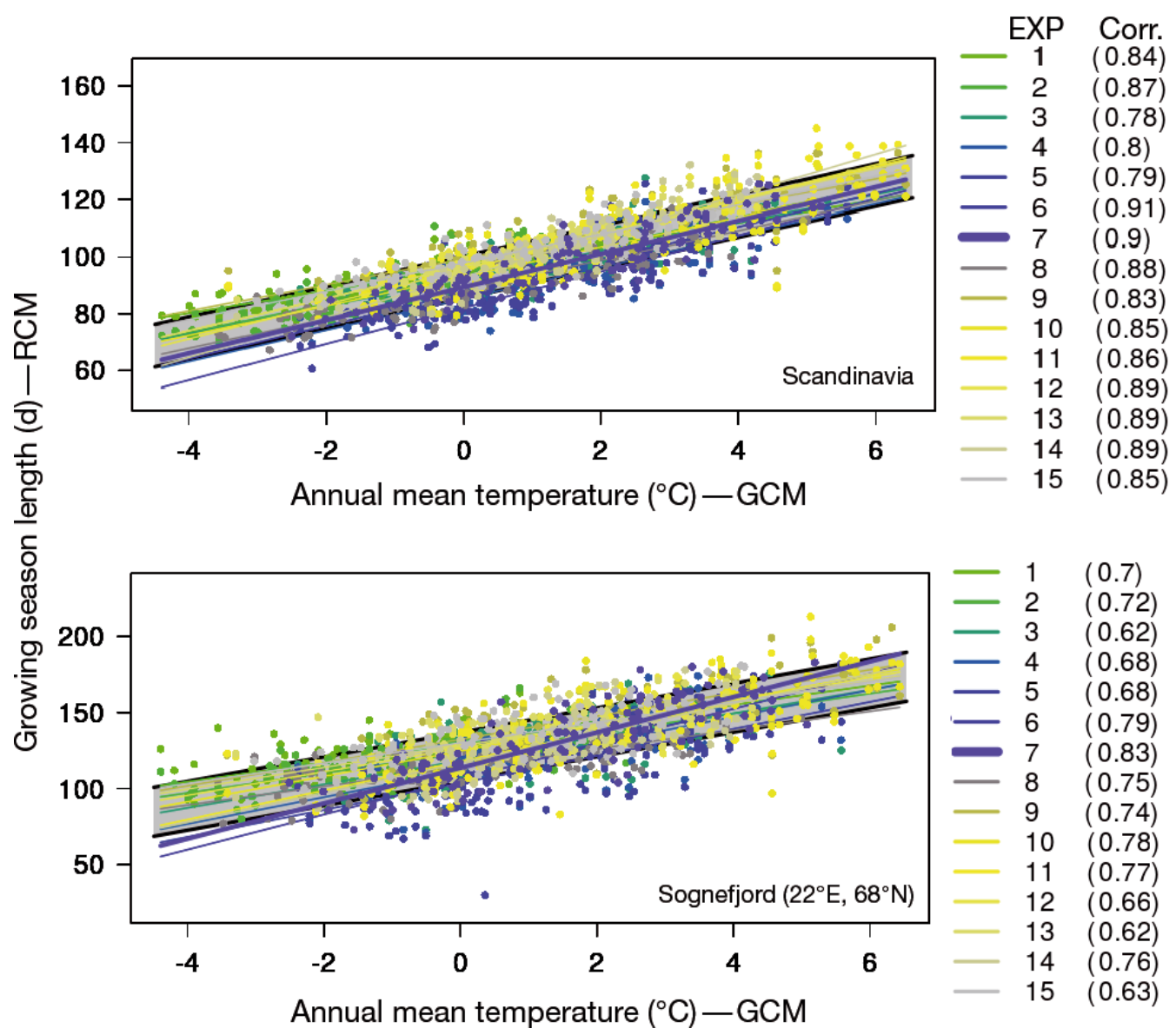

Fig. 7. Growing season length calculated from 15 EURO-CORDEX simulations for Scandinavia (top) and for Sognefjord (bottom) correlated with annual mean temperature from the respective forcing global climate models for the RCP8.5 scenario experiments from 2006 to 2100 . The grey shaded area represents the likely prediction interval of the entire index-temperature population. EXP numbers (right) refer to downscaling experiments listed in Table 1. Parentheses: correlation coefficient

\section{DISCUSSION}

\subsection{Assumption I}

In Fig. 3 (growing season length), we find a correlation coefficient $(\mathrm{r}=0.78)$ on the local scale enabling uncertainty to be quantified at this high resolution. For Sognefjord, we meet the high correlation requirement anticipated in Assumption I. For growing season onset in Fig. 4, the correlation with annual mean temperature is lower, but still provides valid and useful information for assessing the uncertainties associated with the projected climate index. For the 2 indices shown here, the uncertainty is assessable using the established relationship and the converted CMIP5 temperature changes indicated as vertical shaded areas in Figs. 3 \& 4 .

Not all indices show the same convincingly high temperature dependence as for growing season length and onset, but lower correlation merely results in wider confidence ranges and prediction inter- vals on the index-temperature correlation graph. This means that the uncertainty for a given index depends on the correlation coefficient, where a strong correlation narrows the index uncertainty and a weak correlation expands it. We suggest interpreting this as a realistic feature describing the actual index uncertainty for a future climate projection.

This should be distinguished from the climate index sensitivity of annual mean temperature change, which is indicated by the slope of the regression lines in Figs. 3 \& 4. Strong dependency (steep slope) increases the likely index uncertainty range, whereas weak temperature dependency (shallow slope) decreases the index uncertainty for a constant correlation coefficient.

From Fig. 2, it is clear that EC-Earth shows a significantly larger temperature increase than other CMIP5 members. Almost all annual mean temperatures from EC-Earth 2081-2100 (based on RCP4.5 and RCP8.5, in total 40 points on the plot) exceed the general CMIP5 spread. An important factor here is 


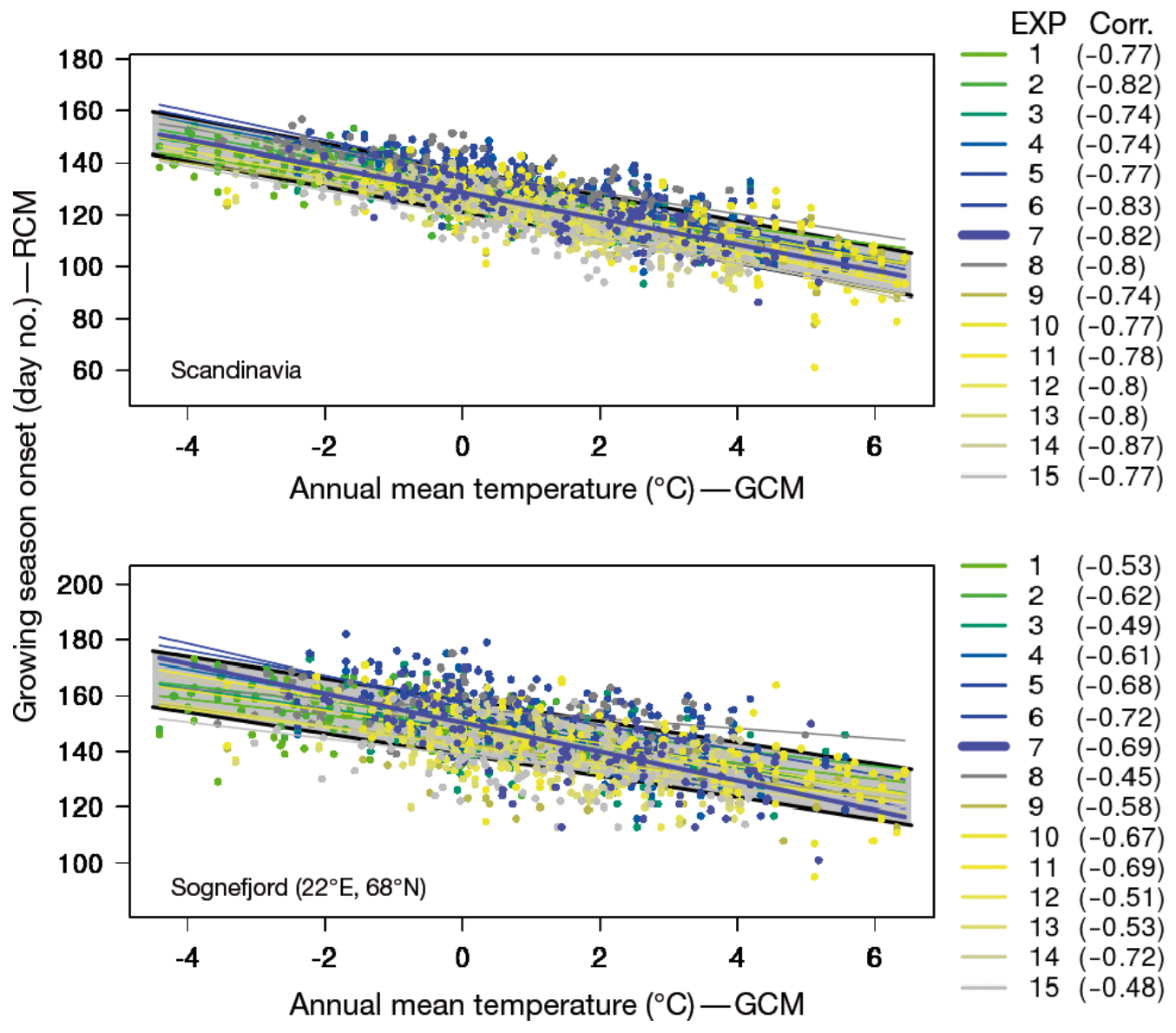

Fig. 8. As Fig. 7 but for growing season onset

that EC-Earth simulates the 21st century about $2^{\circ} \mathrm{C}$ colder in the Arctic, related to an excessive Arctic sea ice cover, and therefore also a larger temperature increase in the Arctic area when sea ice starts to disappear (Koenigk et al. 2013).

However, this will not affect the correlation and shape of the regression line because the index is de-

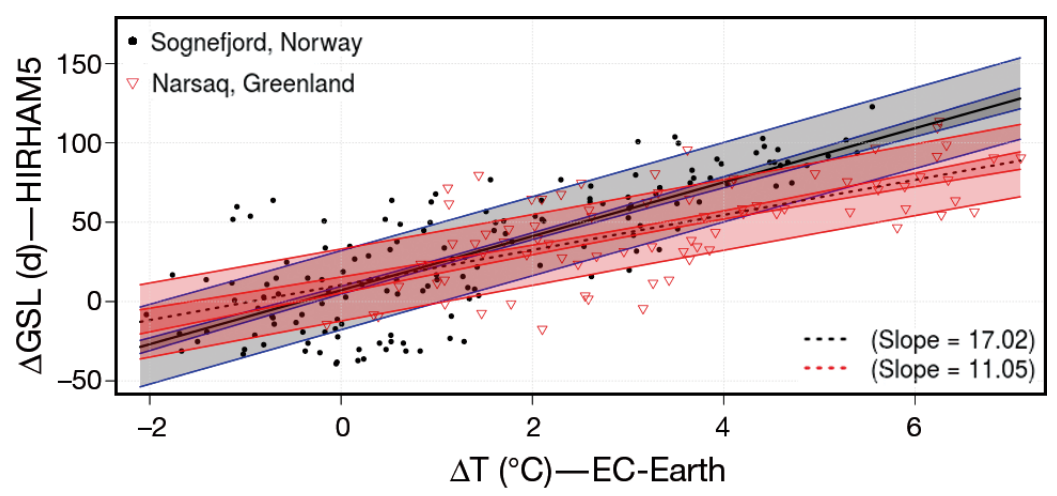

Fig. 9. Growing season length (GSL) from HIRHAM5 as a function of annual mean temperature (T) from EC-Earth for Sognefjord (black) and Narsaq (red). The black lines represent the best fit regression lines for each data set. Light and dark shaded areas are the likely prediction and confidence intervals, respectively rived from HIRHAM5 in matching warmer conditions. On the other hand, this method actually avoids overestimating the expected change in length of the growing season. So this adds to the benefits of using the proposed uncertainty quantification method.

\subsection{Assumption II}

RCM-conducted climate indices exhibit statistically significant and good correlations with their forcing GCMs for the entire CORDEX ensemble. The correlation for each CORDEX member is evidently larger when considering all of Scandinavia than for a selected location.

In Figs. 7 \& 8, all regression models show the same tendency. By merging all data points for the $15 \mathrm{RCMs}$, the majority of the individual regression lines fall within the $66 \%$ prediction range (the grey shaded areas in Figs. 7 

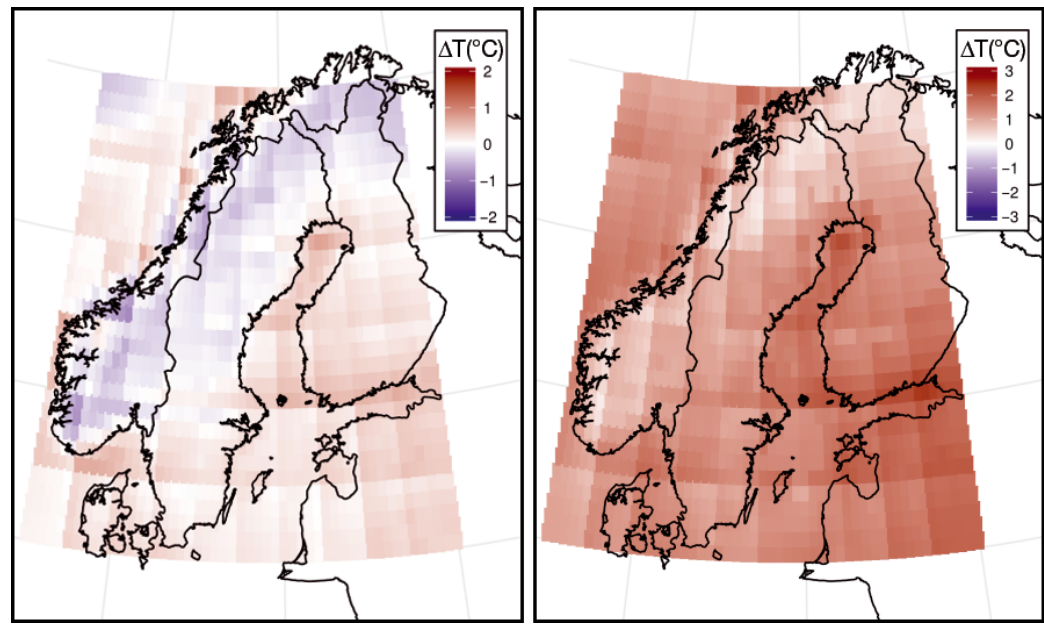

Fig. 10. Differences in low-end projections (17th percentiles, left) and highend projections (83rd percentiles, right) between CMIP5 and CORDEX projected annual mean temperature $(\mathrm{T})$ changes for the RCP8.5 scenario from $1986-2005$ to $2081-2100$

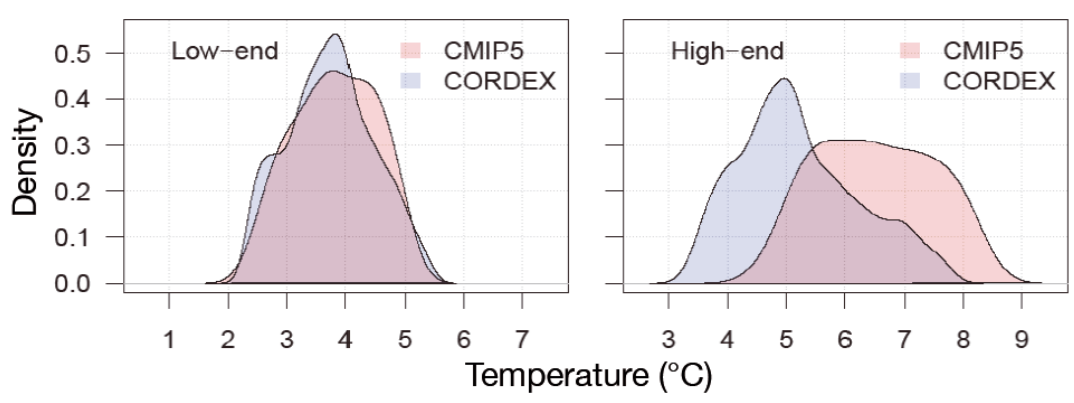

Fig. 11. Density plot of CMIP5 and CORDEX temperature changes from 19862005 to 2081-2100 for all Scandinavian grid points. Left shows low end of likely range (17th percentile) and right shows high end of likely range (83rd percentile)

\& 8) for Scandinavia in general but also for the specific Sognefjord grid point. However, some of the regressions escape the prediction interval for low- and highend GCM temperatures, especially for temperatures outside the projected range for the given GCM.

The analysis and quantification of climate index uncertainties should be done for limited areas or even at grid point level to benefit optimally from the high-resolution climate change simulation. By considering areas that are too large, the added information value from the GCM downscaling will be lost (Rockel 2015).

HIRHAM5 is indistinguishable from the CORDEX ensemble, where according to Jacob et al. (2014), projected temperature changes within CORDEX are significant according to a $t$-test or Mann-WhitneyWilcoxon test, and also robust, with $>66 \%$ of the models agreeing on the direction of projected temperature changes.

\subsection{Assumption III}

Fig. 9 together with Figs. $5 \& 6$ illustrate that the climate index temperature relation calculated from HIRHAM5 and EC-Earth is statistically significant for Narsaq in Greenland and Sognefjord in Norway and for the entire Scandinavian domain. Figs. $7 \& 8$ show that the latter holds for the entire CORDEX ensemble, and this gives us confidence in assuming the same relationship holds for Greenland.

Fig. 9 shows that the correlation is kept for the 2 locations; however, the different slopes indicate different temperature sensitivities for Narsaq and Sognefjord. This emphasises the importance of analysing every grid point of interest separately, to ensure reliable estimates of climate index changes and associated uncertainty estimates.

\subsection{Assumption IV}

The likely range of CORDEX temperature changes is to a large extent captured by CMIP5 projected temperature changes. In Figs. 10 \& 11, the 83rd percentile temperature projections from CMIP5 are clearly larger than those from CORDEX, which is required to ensure that CMIP5 embraces the high end of the CORDEX likely range. Likewise, the difference between the CMIP5 and CORDEX low-end projections should be negative or close to zero to ensure that CMIP5 also captures the low end from CORDEX. This is only true for approximately half the land points in Scandinavia; however, positive areas in Fig. 10 do not exceed $0.5^{\circ} \mathrm{C}$ and are confined to areas with little topography (Greenland in general has a complex topography similar to the Norwegian west coast). The relatively small difference is also illustrated in the density plots in Fig. 11. The fact that CMIP5 consists of 39 GCMs whereas only 5 GCMs are downscaled within CORDEX is probably the main reason why CMIP5 to a large extent embraces the variance of CORDEX. By selecting 5 of $39 \mathrm{GCMs}$, the 83rd percentile will probably decrease and the 17 th percentile increase because of the model selec- 
tion itself. Applying the CMIP5 ensemble mean and likely range for projected temperature changes as an estimate of expected temperature changes will almost cover the expected likely range of CORDEX temperature changes. The role of boundary conditions from the GCM is generally greater than the role of the RCM, in particular for temperature (Déqué et al. 2007).

This argument is supported by the box and whisker plots in Fig. 12 that show the upper and lower quantiles and upper and lower bounds of RCM projected annual mean temperatures divided between 5 different GCMs for Scandinavia and Sognefjord. The GCMs introduce the first levels of uncertainty propagation from large- to small-scale temperature projections. In Fig. 12, the individual GCMs show different characteristics in terms of median values and $50 \%$ likely ranges. The differences or uncertainties are mainly caused by the GCM global energy budget and the climate sensitivity, which again is influenced by factors such as atmospheric stability and cloud feedback mechanisms (Lenderink et al. 2007, Kjellström et al. 2013). The next level of uncertainty is introduced by the RCMs in terms of small-scale physical processes such as small-scale convection and fine-scale interactions involving orography and land-sea transitions. The RCMs in Fig. 12 also tend to show only limited divergence from their driving GCM, indicating that the GCMs to a large extent control the temperature changes. This was in fact a main motivation for the design of the method proposed in the present study.

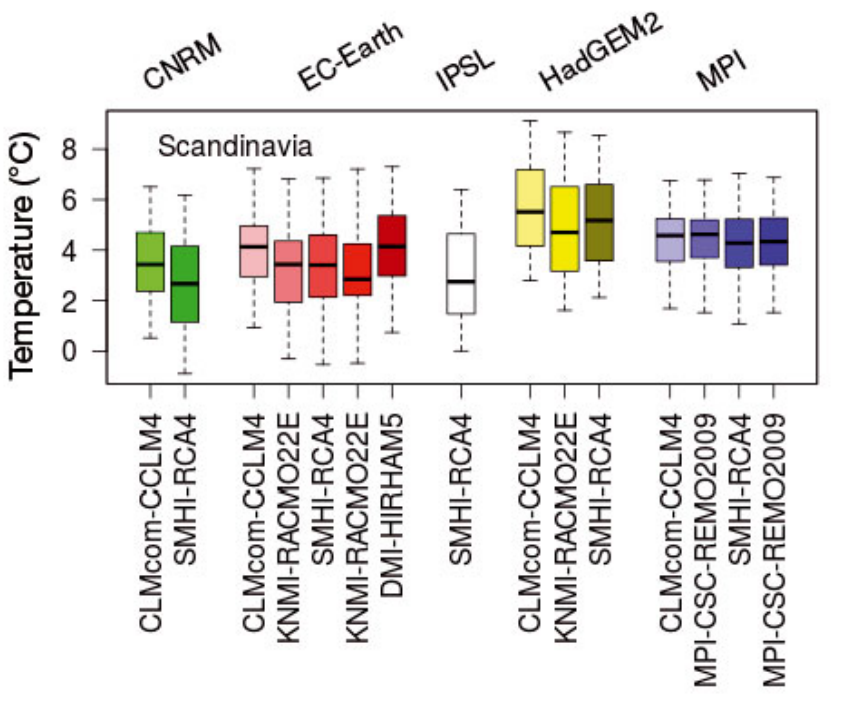

\subsection{Uncertainty assessment technique in general}

In addition to temperature-dependent climate indices, we also looked into precipitation-derived climate indices (not shown). Correlations were tested against GCM temperature and GCM precipitation. This demonstrated some limitations of this approach as an uncertainty quantification method. The precipitation-derived indices do not show statistically significant correlation with temperature projections. However, some precipitation-dependent indices do correlate with annual mean precipitation, but the inter-model likely range of CMIP5 precipitation projections is relatively large. Hence, in practice, converting that into index uncertainty appears unusable or at best serves to underline the relatively large uncertainty that always appears to be associated with regional precipitation projections. On regional and very local scales, we do not necessarily expect the precipitation to scale with the increasing global annual mean temperature predicted by the GCMs. Precipitation sensitivity to global warming can even be smaller in an emission scenario with larger greenhouse gas concentrations and aerosol emissions (Shiogama et al. 2010). Hence, the amount of precipitation is dependent on parameters other than temperature.

That being said, when changes in a given climate index are not correlated with the general temperature changes, the changes may not be significant at all, and may be mostly an artefact of natural variability. So, one might argue that with our method, all

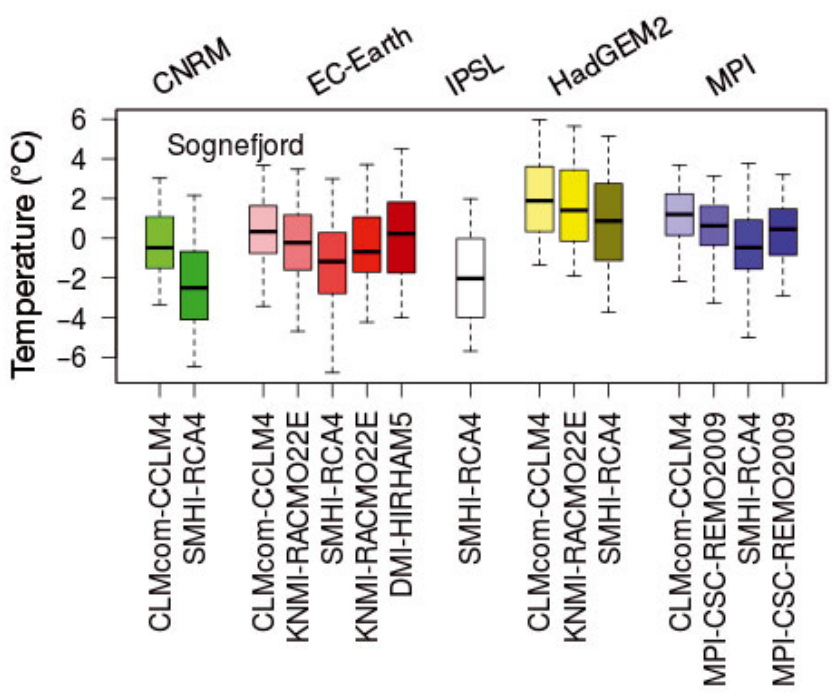

Fig. 12. Annual mean temperature for 2006-2100 for the RCP8.5 scenario simulated with the RCMs in CORDEX (see Table 1), for Scandinavia (left) and Sognefjord (right). The driving models are grouped by colour (green: CNRM-CERFACS-CNRM-CM5; red: ICHEC-EC-EARTH; white: IPSL-ENERIS; yellow: MOHC-HadGEM2-ES; blue: MPI-M- MPI-ESM-LR). Boxplots - midline: median; box: interquartile range; whiskers: lower and upper extreme values 
changes in relevant climate indices are assessable, but the resulting change may be seen as being not statistically significant, and exhibiting a large year-toyear variation. The change in consecutive dry days (see Fig. 14) is an example of that.

The reports mentioned in the 'Introduction' (Christensen et al. 2015) present changes in more than 60 different indices for 2031-2050 and 2081-2100 for RCP4.5 and RCP8.5 relative to the historical period 1991-2010 based on dynamical downscaling with HIRHAM5 to $5.5 \mathrm{~km}$. Corresponding uncertainties have been quantified applying a variant of the method presented here. However, the indices are derived from daily temperature, precipitation, humidity and wind projections, and do not all correlate well (if at all) with annual mean temperature changes in the driving GCM. Practically all climate indices which are not derived from temperature do not show the statistically significant correlation to annual mean temperature required to take advantage of this uncertainty assessment method.

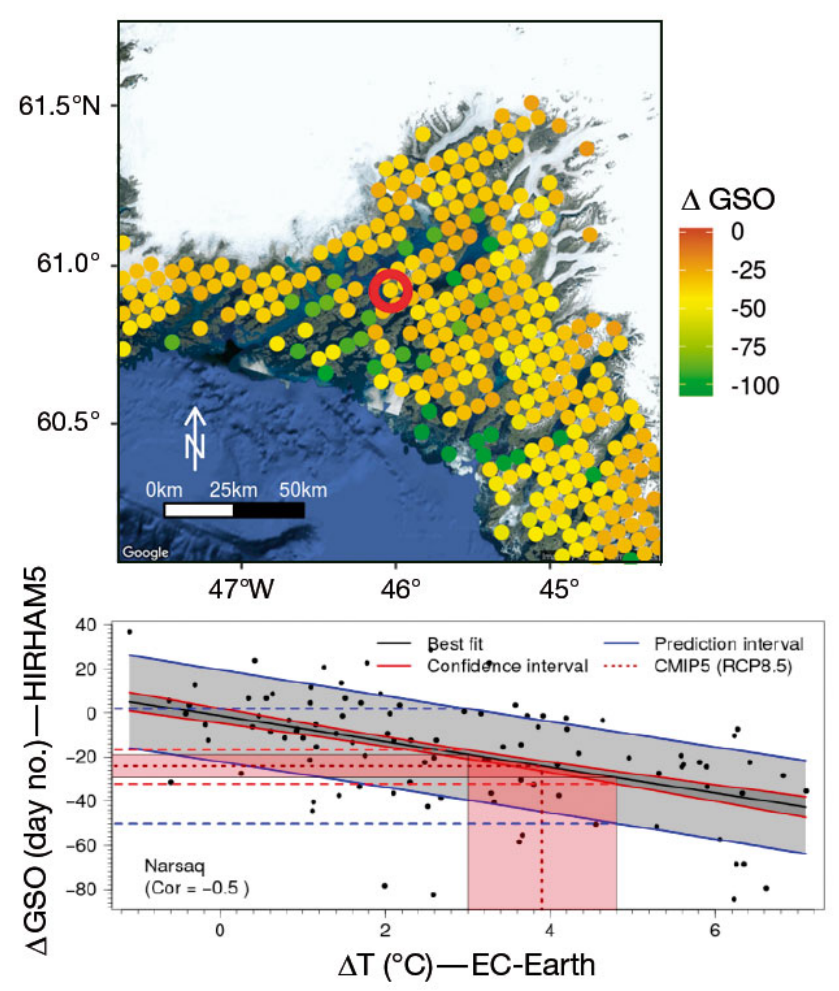

In the attempt to develop and optimise the uncertainty assessment method, we had to choose between HIRHAM5-derived climate indices and 1 of 3 possible index-temperature correlations: (1) HIRHAM5 simulated annual mean temperature changes, (2) CMIP5 annual mean temperature changes, or (3) the forcing GCM, EC-Earth simulated annual mean temperature.

The first solution clearly results in the highest correlation coefficients, but the link to CMIP5 mean values and uncertainty information disappears. For the indices shown in Fig. 13, it would be unknown if the relatively high increase in annual mean temperature compared to CMIP5 originated from the GCM or from the RCM.

The second suggestion results in correlation coefficients that are too low, caused by the altered year-toyear variability as well as differences in topography and land-sea masks due to the jump in resolution between the driving model and the regional model.

The third option offering the highest possible correlation coefficient keeping the link to CMIP5

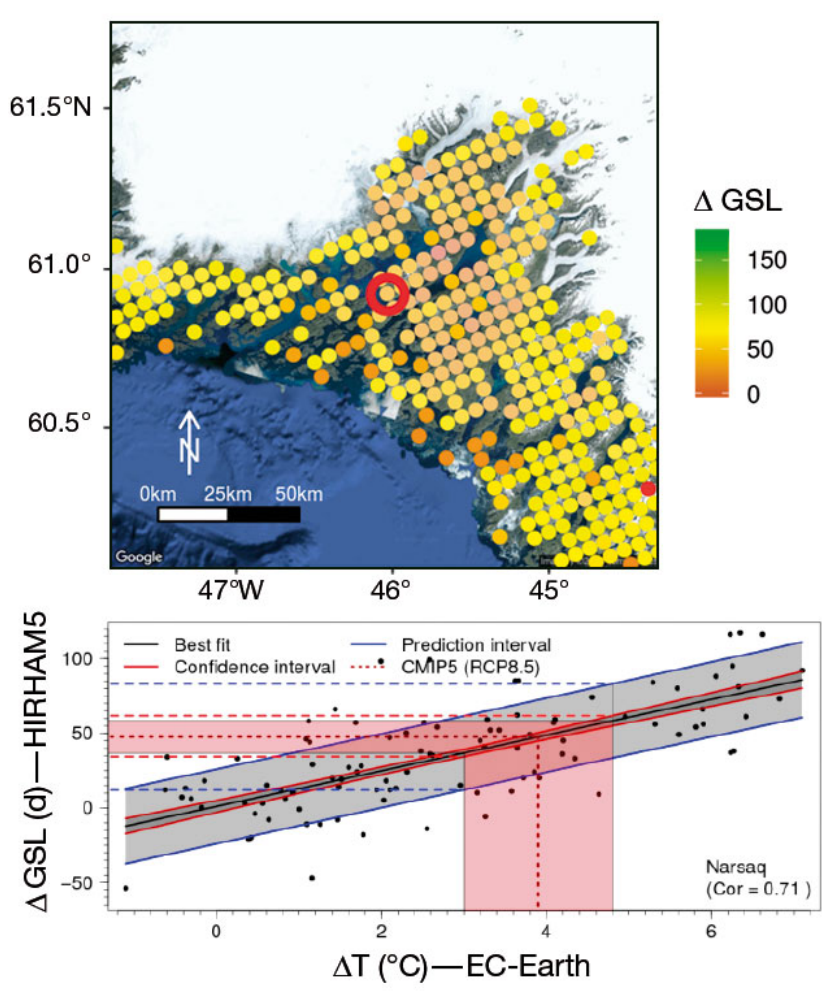

Fig. 13. Projected changes in growing season onset (GSO, left) and growing season length (GSL, right). The maps show changes for 2081-2100 relative to 1991-2010 for RCP8.5 for the area around Narsaq (red circle on the maps) in southern Greenland. The graphs show changes in annual indices from HIRHAM5 as a function of annual mean temperature (T) changes from EC-Earth. Each point represents one year within 2031-2050 and 2081-2100 relative to 1991-2010 for RCP4.5 and RCP8.5. CMIP5 ensemble mean (and likely ranges) temperature changes from 1991-2010 to 2081-2100 are displayed as vertical red dashed lines and red shaded areas. The black, red and blue lines are the best fitted linear regression model, its confidence interval and its prediction interval, respectively. The blue dashed lines represent projected prediction intervals. 
through the forcing GCM was therefore preferred. GCM-RCM comparison analysis (not shown) shows significant differences between HIRHAM5 and ECEarth for Scandinavia both for absolute and for delta change values. Therefore, the link to the global models is required to ensure the full likely range for projected climate index changes.

Another way to improve the uncertainty assessment technique could be by correlating growing season onset from HIRHAM5 with mean spring temperature from the driving model EC-Earth, and using the available spring temperature variances from CMIP5. This will, through higher correlation coefficients, provide projections that are less uncertain. Likewise, growing season length could be correlated with relevant months from the GCM. However, this is beyond the scope of the present study. The main reason for scaling with global annual mean temperature is that it scales better with global annual mean temperature than does the seasonal mean, which also allows for better scale results between models (e.g. see Lynch et al. 2017, Osborn et al. 2018).

\section{APPLICATION TO GREENLAND}

The uncertainty assessment method is here applied for agriculture-relevant climate indices in southern Greenland around Narsaq (see inset map in Fig. 1). Here we present projected changes in the climate indices growing season length and onset, frost days and consecutive dry days, and quantify the corresponding uncertainties using the propounded technique.

If we follow the RPC8.5 scenario, an extension of growing season in Narsaq of $48 \mathrm{~d}$ towards the end of this century compared to $1991-2010$ is expected. The corresponding uncertainty displayed in Fig. 13 is assessed to be $\pm 15 \mathrm{~d}$ (see Table 2). The uncertainty estimate takes into account the likely range of pro-

Table 2. Projected changes in climate indices relevant for agriculture in Narsaq and the surrounding area

\begin{tabular}{|lrcc|}
\hline $\begin{array}{l}\text { Index } \\
\text { (d) }\end{array}$ & $\begin{array}{r}\text { Index } \\
\text { change }\end{array}$ & $\begin{array}{c}\text { CMIP5- } \\
\text { related } \\
\text { uncer- } \\
\text { tainty }\end{array}$ & $\begin{array}{c}\text { Total } \\
\text { uncertainty } \\
\text { (CMIP5 + } \\
\text { year to year) }\end{array}$ \\
\hline Length of growing season & 52 & 15 & 36 \\
Onset of growing season & -25 & 7 & 15 \\
Frost days & -32 & 9 & 19 \\
Consecutive dry days & -1 & 2 & 10 \\
\hline
\end{tabular}

jected CMIP5 simulations (horizontal red dashed lines in Fig. 13). The year-to-year variability from HIRHAM5 combined with the CMIP5 likely range is shown with the horizontal blue dashed lines. The likely range of the projected change in growing season length in Narsaq, including the year-to-year variability, is with this method projected to be $52 \pm 36 \mathrm{~d}$. This implies that even for years with a short growing season, by the end of this century, they will be longer than today's average length.

The growing season is with HIRHAM5 expected to start almost 1 mo earlier by the end of the 21st century compared to $1990-2010(-25 \pm 7 \mathrm{~d})$, including the likely spread of CMIP5, and $-25 \pm 15 \mathrm{~d}$ also including the year-to-year variability (see Fig. 13). Equivalently, the amount of frost days displayed in Fig. 14 is expected to decrease by $32 \pm 9 \mathrm{~d}$ including the likely CMIP5 spread and $32 \pm 19 \mathrm{~d}$ also including the year-to-year variability. For consecutive dry days, the HIRHAM5 simulation identifies no statistically significant changes towards year $2100(-1 \pm 2 \mathrm{~d}$ and \pm 10 d) compared to 1991-2010 (see Fig. 14). This index does not correlate with annual mean temperature $(\mathrm{r}=-0.04)$; therefore, the uncertainty of $\pm 10 \mathrm{~d}$ exclusively represents the year-to-year variability, which is not expected to change during this century.

As described in Section 1, the method prepares the ground for different index uncertainty interpretations. One useful application here is the estimated change in the length of the growing season, including the likely range based on the CMIP5 estimates of the projected index. The year-to-year variability can be compared to present-day local conditions in order to acertain if the result is consistent with observations. Projected changes for the 4 mentioned indices are listed in Table 2.

The projected index change and uncertainty can also be assessed for a given temperature increase. A $2^{\circ} \mathrm{C}$ warming for the area around Narsaq will expand the growing season by approximately $26 \pm 24 \mathrm{~d}$ (Fig. 13, bottom right) including the likely prediction range. In the same way, changes in onset of growing season and number of frost nights are projected and evaluated.

Projected changes in growing season length and frost days towards the end of the 21st century in southern Greenland will make it possible to grow new crops with a short growing season, such as barley. The climate change also provides a longer growing season for potatoes and vegetables; however, the dominant crop in Greenland will probably still be pasture by the end of this century (Lehmann et al. 2017). 

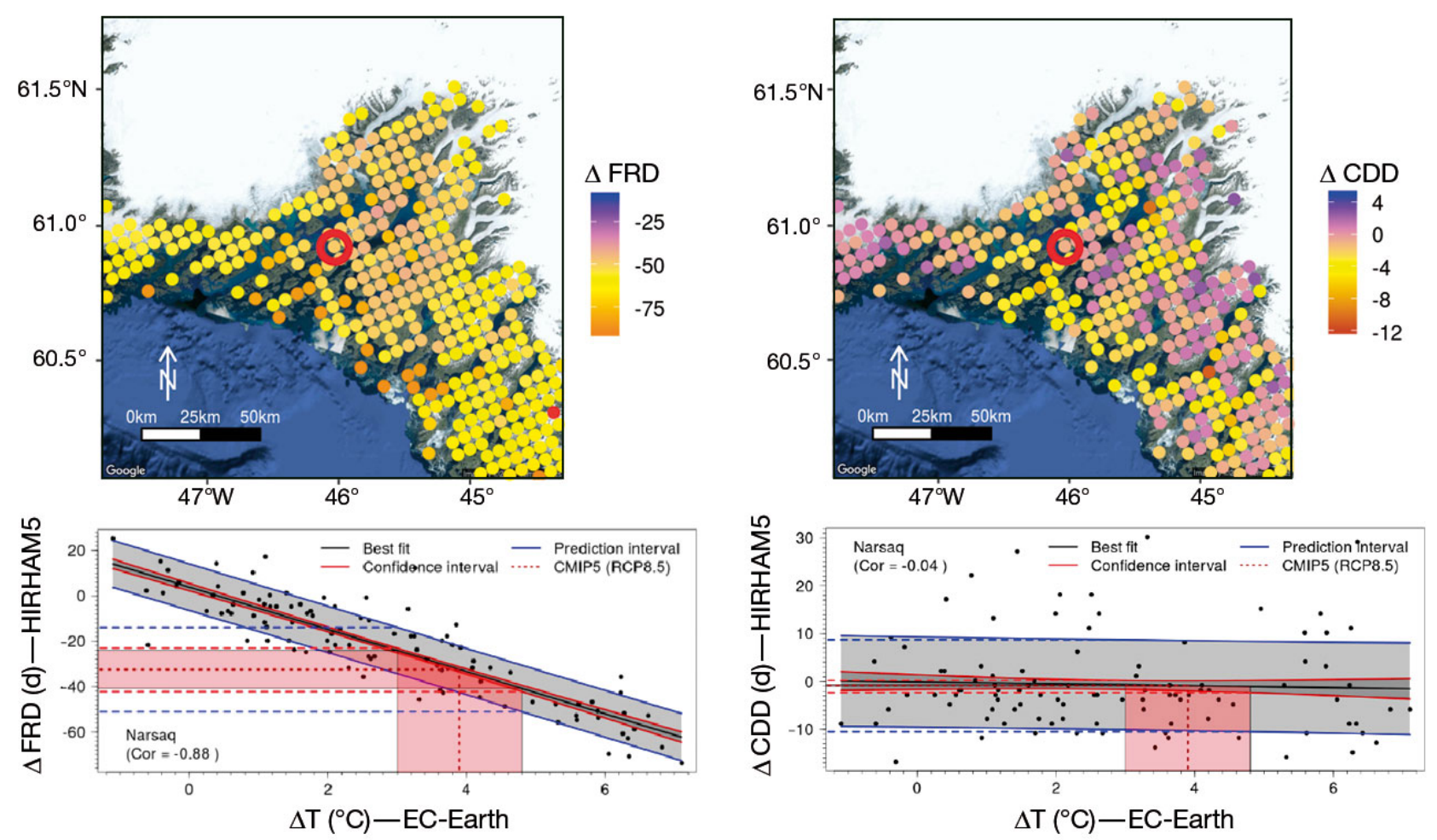

Fig. 14. Projected changes in number of annual frost days (FRD; left) and longest period with consecutive dry days (CDD; right) for 2081-2100 relative to 1991-2010 for the RCP8.5 scenario in Narsaq (red circle on the maps) and the surroundings. The graphs (bottom) show the relationship between the climate index from HIRHAM5 and annual mean temperature from EC-Earth for the ice free land point nearest Nasaq. Each point represents one year within the time slices 1991-2010, 20312050 and 2081-2100 for the scenarios RCP4.5 and RCP8.5. Black, red and blue lines: best fitted regression line, its confidence interval and prediction intervals, respectively. The CMIP5 projected temperature change for the RCP8.5 scenario in 2081-2100, including its likely spread, is indicated with vertical short dashed red lines and the red shaded area. Horizontal dashed lines: changes in projected climate index and corresponding likely ranges. The likely spread of CMIP5 mean temperature converted into likely spread of projected index values (red dashed lines) and to likely spread of year-to-year variability (horizontal blue dashed lines)

\section{CONCLUSIONS}

We have analysed a series of GCMs and RCMs and shown that temperature-dependent climate indices correlate well with temperature. In particular, correlations between HIRHAM5-based climate indices and EC-Earth annual mean temperatures can be seen as representative of the full information deducible from the EURO-CORDEX ensemble. We also find that the likely range of projected CMIP5 temperatures is larger than that of projected CORDEX temperatures for the upper end of the likely range, and comparable to CORDEX temperatures for the low end. The spread of projected temperature changes from the CMIP5 ensemble will therefore most likely cover the individual RCM projections for a given location.

Precipitation-related indices at the regional level like consecutive dry days are in general not statistically significantly correlated with annual mean temperatures, but do correlate with annual mean pre- cipitation. Accordingly, the likely range of CMIP5 projected annual mean precipitation is very large compared to projected annual mean temperature. Hence, the uncertainty range will exceed the climate change signal. But this may well depict the state of the art, as model variability in precipitation projection is often very large at the grid point level (IPCC 2013). For the index consecutive dry days, which does not correlate with annual mean temperature, only the likely year-to-year variability can be quantified by use of this uncertainty assessment method.

On the other hand, we find that the spread of CMIP5 annual mean temperature change to a large degree is convertible to the HIRHAM5 projected climate index uncertainty for changes in growing season length and onset and for frost days. The uncertainty assessment method thus utilises uncertainty quantification of projected changes in climate indices from a single RCM for a geographical domain like Greenland, where only one or a few RCMs are available. 
Acknowledgements. We acknowledge the World Climate Research Programme's Working Group on Regional Climate and the Working Group on Coupled Modelling, former coordinating body of CORDEX and responsible panel for CMIP5. We also thank the climate modelling groups (listed in Table 1 of this paper) for producing and making available their model output. The research leading to these results has received funding from the European Research Council under the European Union's Seventh Framework Programme (FP7/2007-2013)/ERC Grant Agreement no. 610055 as part of the ice2ice project and from the Danish Cooperation for Environment in the Arctic (DANCEA) under the Danish Energy Agency.

\section{LITERATURE CITED}

Akperov M, Rinke A, Mokhov II, Matthes H and others (2018) Cyclone activity in the Arctic from an ensemble of regional climate models (Arctic CORDEX). J Geophys Res Atmos 123:2537-2554

AMAP (Arctic Monitoring and Assessment Programme) (2017) Snow, water, ice and permafrost in the Arctic (SWIPA). AMAP, Oslo

Boberg F, Langen PL, Mottram RH, Christensen JH, Olesen M (2017) 21st-century climate change around Kangerlussuaq, west Greenland: from the ice sheet to the shores of Davis Strait. Arct Antarct Alp Res 50:S100006

Christensen JH, Christensen OB (2003) Severe summertime flooding in Europe. Nature 421:805-806

Christensen JH, Hewitson B, Busuioc A, Chen A and others (2007) Regional climate projections, Chap. 11. In: Solomon S, Qin D, Manning M, Chen Z and others (eds) Climate change 2007: the physical science basis. Contribution of Working Group I to the Fourth Assessment Report of the Intergovernmental Panel on Climate Change. Cambridge University Press, Cambridge, p 847-940

Christensen JH, Boberg F, Christensen OB, Lucas-Picher P (2008) On the need for bias correction of regional climate change projections of temperature and precipitation. Geophys Res Lett 35:L20709

Christensen JH, Olesen M, Boberg F, Stendel M, Koldtoft I (2015) Fremtidige klimaforandringer I Grønland: Qeqqata kommune. Tech Rep 15-04, Danish Meteorological Institute, Copenhagen

* Christensen OB, Christensen JH, Machenhauer B, Botzet M (1998) Very high-resolution regional climate simulations over Scandinavia — present climate. J Clim 11:3204-3229

Christensen OB, Drews M, Christensen JH, Dethloff K, Ketelsen K, Hebestadt I, Rinke A (2006) The HIRHAM regional climate model. Version 5 (beta). Tech Rep 06-17, Danish Meteorological Institute, Copenhagen

Collins WJ, Bellouin N, Doutriaux-Boucher M, Gedney N and others (2011) Development and evaluation of an Earth-system model-HadGEM2. Geosci Model Dev 4: 1051-1075

*DDee DP, Uppala SM, Simmons AJ, Berrisford P and others (2011) The ERA-Interim reanalysis: configuration and performance of the data assimilation system. QJR Meteorol Soc 137:553-597

ํóqué M (2007) Frequency of precipitation and temperature extremes over France in an anthropogenic scenario: model results and statistical correction according to observed values. Global Planet Change 57:16-26

* Déqué M, Rowell DP, Lüthi D, Giorgi F and others (2007) An intercomparison of regional climate simulations for Europe: assessing uncertainties in model projections. Clim Change 81:53-70

DFFL (Departementet for Fiskeri, Fangst og Landbrug) (2007) Visioner for det Grønlandske landbrug. Departementet for Fiskeri, Fangst og Landbrug, Nuuk

* Di Luca A, de Elía R, Laprise R (2015) Challenges in the quest for added value of regional climate dynamical downscaling. Curr Clim Change Rep 1:10-21

*Doufresne JL, Foujols MA, Denvil S, Caubel A and others (2013) Climate change projections using the IPSL-CM5 Earth system model: from CMIP3 to CMIP5. Clim Dyn 40:2123-2165

* Feser F, Rockel B, von Storch H, Winterfeldt J, Zahn M (2011) Regional climate models add value to global model data: a review and selected examples. Bull Am Meteorol Soc 92:1181-1192

*Giorgetta MA, Jungclaus J, Reick CH, Legutke S and others (2013) Climate and carbon cycle changes from 1850 to 2100 in MPI-ESM simulations for the Coupled Model Intercomparison Project Phase 5. J Adv Model Earth Syst 5:572-597

* Giorgi F, Mearns LO (2003) Probability of regional climate change based on the reliability ensemble averaging (REA) method. Geophys Res Lett 30:1629

Giorgi F, Jones C, Asrar GR (2009) Addressing climate information needs at the regional level: the CORDEX framework. WMO Bull 58:175-183

Giorgi F, Torma C, Coppola E, Ban N, Schär C, Somot S (2016) Enhanced summer convective rainfall at alpine high elevations in response to climate warming. Nat Geosci 9:584-589

* Giot O, Termonia P, Degrauwe D, De Troch R and others (2016) Validation of the ALARO-0 model within the EURO-CORDEX framework. Geosci Model Dev 9: 1143-1152

* Hazeleger W, Wang X, Severijns C, Ştefănescu S and others (2012) EC-Earth V2.2: description and validation of a new seamless earth system prediction model. Clim Dyn 39:2611-2629

IPCC (2013) Stocker TF, Qin D, Plattner GK, Tignor M and others (eds) Climate change 2013: the physical science basis. Working Group I Contribution to the Fifth Assessment Report of the Intergovernmental Panel on Climate Change. Cambridge University Press, Cambridge

Jacob D, Elizalde A, Haensler A, Hagemann S and others (2012) Assessing the transferability of the regional climate model REMO to different COordinated Regional Climate Downscaling EXperiment (CORDEX) regions. Atmosphere 3:181-199

Jacob D, Petersen J, Eggert B, Alias A and others (2014) EURO-CORDEX: new high-resolution climate change projections for European impact research. Reg Environ Change 14:563-578

*Kjellström E, Thejll P, Rummukainen M, Christensen JH, Boberg F, Christensen OB, Maule CF (2013) Emerging regional climate change signals for Europe under varying large-scale circulation conditions. Clim Res 56:103-119

Koenigk T, Brodeau L, Graversen RG, Karlsson J and others (2013) Arctic climate change in 21st century CMIP5 simulations with EC-Earth. Clim Dyn 40:2719-2743

Kupiainen M, Samuelsson P, Jones C, Jansson C and others (2011) Rossby Centre regional atmospheric model, RCA4. Rossby Centre Newsletter, Swedish Meteorological and Hydrological Institute, Norrköping. www.smhi.se/en/ 
research/research-departments/climate-research-rossbycentre2-552/rossby-centre-regional-atmospheric-modelrca4-1.16562

Langen PL, Mottram RH, Christensen JH, Boberg F and others (2015) Quantifying energy and mass fluxes controlling Godthåbsfjord freshwater input in a 5-km simulation (1991-2012). J Clim 28:3694-3713

Lehmann JO, Sharif B, Kjeldsen C (2017) Mulighed for klimatilpasning i landbrugserhvervet - status og handlemuligheder. http://naalakkersuisut.gl/ /media/Nanoq/Files/ Attached \%20Files/Klima/Klimatilpasning \% 20Land brug/Klimatilpasningsredeg \% C3\%B8relse \% 20-\% 20 dansk\%20-\%2020170519.pdf

Lenderink G, van Ulden A, van den Hurk B, Keller F (2007) A study on combining global and regional climate model results for generating climate scenarios of temperature and precipitation for the Netherlands. Clim Dyn 29: 157-176

Lucas-Picher P, Wulff-Nielsen M, Christensen JH, Aðalgeirsdóttir G, Mottram R, Simonsen SB (2012) Very high resolution regional climate model simulations over Greenland: identifying added value. J Geophys Res 117: D02108

Kynch C, Hartin C, Bond-Lamberty B, Kravitz B (2017) An open-access CMIP5 pattern library for temperature and precipitation: description and methodology. Earth Syst Sci Data 9:281-292

Maraun D (2016) Bias correcting climate change simulations - a critical review. Curr Clim Change Rep 2:211-220

Mastrandrea MD, Mach KJ, Plattner GK, Edenhofer O and others (2011) The IPCC AR5 guidance note on consistent treatment of uncertainties: a common approach across the working groups. Clim Change 108:675-691

Mayer S, Maule CF, Sobolowski S, Christensen OB and others (2015) Identifying added value in high-resolution climate simulations over Scandinavia. Tellus A Dyn Meteorol Oceanogr 67:24941

McSweeney CF, Jones RG, Lee RW, Rowell DP (2015) Selecting CMIP5 GCMs for downscaling over multiple regions. Clim Dyn 44:3237-3260

Mitchell JFB, Johns TC, Eagles M, Ingram WJ, Davis RA (1999) Towards the construction of climate change scenarios. Clim Change 41:547-581

Osborn TJ, Wallace CJ, Lowe JA, Bernie D (2018) Performance of pattern-scaled climate projections under highend warming. I. Surface air temperature over land. J Clim 31:5667-5680

Pan Z, Christensen JH, Arritt RW, Gutowski WJ, Takle ES, Otieno F (2001) Evaluation of uncertainties in regional

Editorial responsibility: Filippo Giorgi,

Trieste, Italy climate change simulations. J Geophys Res Atmos 106: 17735-17751

Persson G, Bärring L, Kjellström E, Strandberg G, Rummukainen M (2007) Climate indices for vulnerability assessments (No. 111). Swedish Meteorological and Hydrological Institute, Norrköping

* Pithan F, Mauritsen T (2014) Arctic amplification dominated by temperature feedbacks in contemporary climate models. Nat Geosci 7:181-184

* Rockel B (2015) The regional downscaling approach: a brief history and recent advances. Curr Clim Change Rep 1: $22-29$

Rockel B, Will A, Hense A (2008) The regional climate model COSMO-CLM (CCLM). Meteorol Z (Berl) 347-348

Rosen J (2016) Cold truths at the top of the world. Nature 532:296-299

* Rummukainen M (2016) Added value in regional climate modeling. Wiley Interdiscip Rev Clim Change 7:145-159

Samuelsson P, Jones CG, Will'En U, Ullerstig A and others (2011) The Rossby Centre regional climate model RCA3: model description and performance. Tellus A Dyn Meteorol Oceanogr 63:4-23

Shiogama H, Emori S, Takahashi K, Nagashima T, Ogura T, Nozawa T, Takemura T (2010) Emission scenario dependency of precipitation on global warming in the MIROC3.2 Model. J Clim 23:2404-2417

* Sloth Madsen M, Maule CF, MacKellar N, Olesen JE, Christensen JH (2012) Selection of climate change scenario data for impact modelling. Food Addit Contam Part A 29: 1502-1513

Taylor KE, Stouffer RJ, Meehl GA (2012) An overview of CMIP5 and the experiment design. Bull Am Meteorol Soc 93:485-498

Tebaldi C, Arblaster JM (2014) Pattern scaling: its strengths and limitations, and an update on the latest model simulations. Clim Change 122:459-471

van Meijgaard E, van Ulft LH, Lenderink G, De Roode SR, Wipfler EL, Boers R, van Timmermans RMA (2012) Refinement and application of a regional atmospheric model for climate scenario calculations of western Europe. Rep No. KvR 054/12, Programme Office, Climate changes Spatial Planning, Nieuwegein

*Vautard R, Gobiet A, Sobolowski S, Kjellström E and others (2014) The European climate under a $2^{\circ} \mathrm{C}$ global warming. Environ Res Lett 9:034006

*Voldoire A, Sanchez-Gomez E, Mélia DS, Decharme B and others (2013) The CNRM-CM5.1 global climate model: description and basic evaluation. Clim Dyn 40: 2091-2121

Submitted: March 19, 2018; Accepted: September 3 ,2018

Proofs received from author(s): November 5, 2018 